\title{
La generación de Vicente Riva Palacio y el quehacer historiográfico
}

\author{
Antonia Pi-Suñer Llorens
}

FFYL-UNAM

\author{
Balance de los logros y los límites que en el ámbito \\ historiográfíco alcanzó la generación de Tuxtepec, la cual \\ es definida siguiendo el modelo establecido por \\ Luis González.
}

Ni rencores por el pasado ni temores por el porvenir

Vicente Riva Palacio

$\mathrm{E}$ n 1878, al disertar sobre la necesidad y conveniencia de estudiar la historia patria, José María Vigil sostenía:

Los pueblos no se constituyen a priori; los pueblos no pueden prescindir de su pasado, única base segura para conocer el presente y preparar el porvenir; de donde se sigue naturalmente que ninguna ignorancia puede ser más funesta para una nación que la que recae sobre los asuntos que le conciernen; porque no sabrá apreciar en su justa medida lo bueno ni lo malo que tiene, quedando sujeta a impresiones pasajeras, que le inspirarán unas veces la loca confianza del que se imagina poderlo todo, y otras, el profundo desaliento que trae consigo la pérdida de las más lisonjeras esperanzas. ${ }^{1}$

En dicho ensayo, publicado en el periódico El Sistema Postal, don José María insistía en lo importante que era

${ }^{1} J o s e ́$ Maria Vigil, "Necesidad y conveniencia de estudiar la historia patria", en Ortega y Medina, Polémicas, 1970, p. 269. 
para los pueblos "mantener aquellos rasgos que constituyen su fisonomía propia, su personalidad en medio del concurso de las.naciones" ${ }^{2}$ Consideraba que en México la transmisión del conocimiento histórico se había hecho de manera lamentable. Por un lado se había inculcado un sentimiento de odio hacia el pasado colonial, anatematizando todo lo que provenía de aquel periodo "sin reflexionar que, sean cuales fueren las ideas que sobre ello se tengan, allí están los gérmenes de nuestras costumbres y de nuestros hábitos"; por otro lado era evidente que existía desde el tiempo de la conquista un menosprecio hacia las razas indígenas, mismas que seguían formando parte de la sociedad y que, por tanto, cabía estudiar. La unión de estos dos sentimientos, continuaba Vigil, había traído como consecuencia el desconocimiento del propio ser y provocado que el pueblo mexicano hubiese caído en "el peor de los vicios", que era el del desprecio propio. ${ }^{3} \mathrm{Ha}$ bía, pues, que cambiar de actitud, y por ello era necesario hacer conocer

a los hijos de México lo que significa en el mundo el pedazo de tierra que ocupan; porque sólo así podrán amarlo, explotarlo e interesarse en su conservación; que sepan el camino que han recorrido nuestros padres para llegar a conquistar la autonomía y las libertades que hoy disfrutamos, pues tal conocimiento no sólo nos hará apreciar los bienes inestimables que poseemos, sino que robustecerá la fe para marchar ha-

${ }^{2}$ Ibid., p. 267.

${ }^{3}$ Ibid., p. 268. cia el porvenir, fortificándonos con el ejemplo de los que nos han precedido y que tuvieron que vencer obstáculos más poderosos que los que hoy se nos presentan. ${ }^{4}$

Si bien estos conceptos fueron expresados en relación con la enseñanza de la historia, a nuestro parecer reflejan también la idea que permeó a la mayoría de las obras historiográficas escritas en aquellos mismos años y que consistió en transmitir una cultura histórica que, a la vez que conciliara a los mexicanos, reafirmase su identidad nacional. Dicha tarea recayó, salvo algunas excepciones, en la generación de Porfirio Díaz o "tuxtepecana", cuyos miembros nacieron entre 1825 y 1840 . Esta elite rectora se encontró a caballo entre la generación de la Reforma, o romántica-liberal, y la de los científicos. Con la primera coincidió en el momento en que ésta se encontraba en su "madurez triunfante", es decir durante la intervención francesa, el imperio de Maximiliano y el restablecimiento de la república. A partir de 1877, momento en que los tuxtepecanos asumieron "la plenitud de mando", convivieron con los jóvenes formados bajo la filosofía positivista, grupo que los relevaría del poder en $1892.5^{5}$

En el presente ensayo nos interesa acercarnos a las características del quehacer historiográfico realizado por esta generación durante las décadas trans-

${ }^{4}$ Ibid., p. 270.

5 Seguimos la teoría de las generaciones del sugerente libro de González y González, La ronda, 1984. 
curridas entre 1867 , año en que se creyó que se iniciaba la tan anhelada reconstrucción nacional, y 1889 , que vio la luz el último tomo de México a través de los siglos, obra con la que culminó, según nos parece, dicho quehacer. En aquellos veinte años la producción histórica fue no sólo muy copiosa sino también muy versátil, y si bien nuestros historiadores compartieron la tarea con algunos miembros de las generaciones anterior y posterior, no cabe duda de que la mayoría de las obras fueron escritas por la elite que nos ocupa.

De los cien miembros que según las cuentas del maestro Luis González y González pertenecieron a esta minoría rectora, sólo nos ocuparemos de aquellos que se interesaron por la historiografia y que desarrollaron sus actividades literarias básicamente en la ciudad de México. Ellos fueron Joaquín García Icazbalceta, Juan de Dios Arias, José María Roa Bárcena, Evaristo Hernández y Dávalos, José María Vigil, Juan A. Mateos, Antonio García Cubas, Francisco Zarco, ${ }^{6}$ Emilio del Castillo Negrete, Vicente Riva Palacio, Ignacio Manuel Altamirano, Ireneo Paz, Matías Romero y Manuel Rivera Cambas. Alargando un poco la fecha límite de nacimiento, añadiremos a Alfredo Chavero, Julio Zárate y Enrique Olavarría y Ferrari, nacidos el primero en 1841 y los

${ }^{6}$ Cabe señalar que, por su fecha de nacimiento, Francisco Zarco perteneció a la generación que nos ocupa; sin embargo, su vertiginosa carrera como periodista y político y el haber muerto en 1869 han llevado a que, por lo general, sea considerado como miembro de la pléyade de la Reforma. dos últimos en $1844 . .^{7}$ Creemos poder hacerlo por dos razones: la primera, porque dificilmente podemos ubicarlos en el grupo cuyas obras se basaron en la filosofia positivista, y la segunda porque su producción más importante se encuentra dentro de los límites cronológicos que abarca el presente ensayo.

Como miembros de una misma generación, hallamos en nuestros personajes varias coincidencias que cabe anotar. De los 17 consignados, sólo cinco fueron originarios de la ciudad de México: García Icazbalceta, Mateos, García Cubas, Riva Palacio y Chavero; once de ellos nacieron y se formaron en provincia y uno en España, para venir más tarde a residir en la capital, incorporándose a su vida cultural y política. En lo que respecta a sus estudios profesionales, doce se matricularon en la carrera de jurisprudencia, mientras que García Cubas y Rivera Cambas fueron ingenieros topógrafos, y el resto fue, en cierta manera, autodidacta. De los 17, sólo dos no estuvieron vinculados con el periodismo político, a saber, García Icazbalceta y García Cubas. Por lo menos siete fueron profesores: Vigil, Castillo Negrete, Altamirano, Rivera Cambas, Chavero, Zárate y Olavarría. Cuatro participaron en la lucha armada contra los fran-

${ }^{7}$ La lista de personajes corresponde a lo que González y González llama "las ligas mayores". Estamos conscientes de que en virtud de la sistematización hemos dejado fuera a algunos autores de libros de texto. Para mayor información sobre los libros de texto en el periodo que nos ocupa, véase la excelente tesis de licenciatura de Roldán Vera, "Conciencia", 1995. 


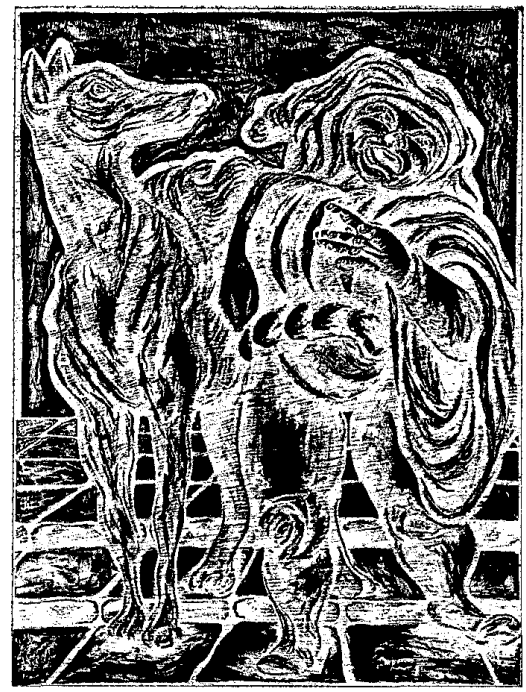

ceses y el segundo imperio: Arias, Riva Palacio, Altamirano y Paz. Respecto a la carrera política, la mayoría tuvo al menos una representación parlamentaria mientras que seis de ellos-Arias, Zarco, Riva Palacio, Romero, Chavero y Zárate- ocuparon cargos públicos importantes. Finalmente, desde el punto de vista ideológico, cabe apuntar que predominó la corriente liberal, ya que de los 17 autores consignados, sólo García Icazbalceta y Roa Bárcena comulgaron con el conservadurismo.

La pequeña revisión estadística que hemos presentado nos muestra la diversidad de actividades desarrolladas por nuestros personajes, quienes combinaron, aparentemente sin problema, la literatura con la política, el periodismo con la acción legislativa, las armas con la oratoria. Eran entonces considerados como literatos $\mathrm{u}$ "hombres de letras", y su actividad literaria no se dividía en compartimentos estancos como ocurre en la actualidad, sino que fue multifacética, por lo que lo mismo escribieron poemas que hicieron traducciones, igual redactaron textos históricos que crónicas teatrales, o elaboraron artículos de costumbres y grandilocuentes piezas de oratoria. Así, el ejercicio de las letras les dio entrada a un vasto campo intelectual que hoy en día ya no se concibe como una unidad.

Como miembros de la elite cultural, nuestros personajes se ocuparon de dar nueva vida a algunas de las sociedades literarias y cientificas que habían dejado de existir en los tiempos de guerra, tanto civil como extranjera. En ellas intercambiaron opiniones y conocimientos con miembros de la pléyade de la reforma con quienes compartieron gustos y principios ideológicos, como fueron el romanticismo y el liberalismo. También lo hicieron con algunos miembros de la generación de los científicos, cuyas nuevas ideas vieron algunos con interés y otros con gran desconfianza.

Las dos asociaciones en que encontramos un mayor número de nuestros personajes fueron El Liceo Hidalgo y la Sociedad Mexicana de Geografia y Estadística. La primera, que fue fundada en 1850 y que, al decir de Alicia Perales, ${ }^{8}$ vivió tres etapas de gran fecundidad para la cultura y las letras mexicanas, contó entre sus miembros a Arias, Roa Bárcena, Zarco, Vigil, García Cu-

8 Perales, Asociaciones, 1957, pp. 89-122. 
bas, Riva Palacio, Altamirano, Paz, Rivera Cambas y Chavero. En cuanto a la segunda, que, como sabemos, también pasó desde su inicio en 1833 por diferentes épocas, unas más fructíferas que otras, en los años que nos ocupan tuvo una producción bastante excepcional. A pesar de que la primera finalidad de esta Sociedad fue puramente científica, con el tiempo se abrió a las contribuciones humanísticas y es por ello que hallamos en su seno un alto porcentaje de los hombres de letras que nos ocupan. A saber, García Icazbalceta, Roa Bárcena, Hernández y Dávalos, Vigil, García Cubas, Riva Palacio, Altamirano, Rivera Cambas, Chavero, Zárate y Olavarría.

Otro importante espacio que com. particron nuestros hombres de letras y en el que también se encontraron con colegas de las generaciones anterior y posterior a la suya, fueron las famosas Veladas Literarias, movimiento cultural que surgió de la efervescencia nacionalista provocada por el triunfo sobre la intervención extranjera. Si bien estas reuniones sólo subsistieron seis meses, de 1867 a 1868 , contribuyeron de manera importante a fomentar el renacimiento de la literatura nacional. Aunque la mayoría de los asistentes eran simpatizantes del partido liberal, participaron también algunos conservadores, especialmente José María Roa Bárcena. El entusiasmo del principal promotor de estas Veladas quedó plasmado en sus "Revistas Literarias":

El movimiento literario es visible. Hace algunos meses todavía, la prensa no publicaba sino escritos políticos u obras

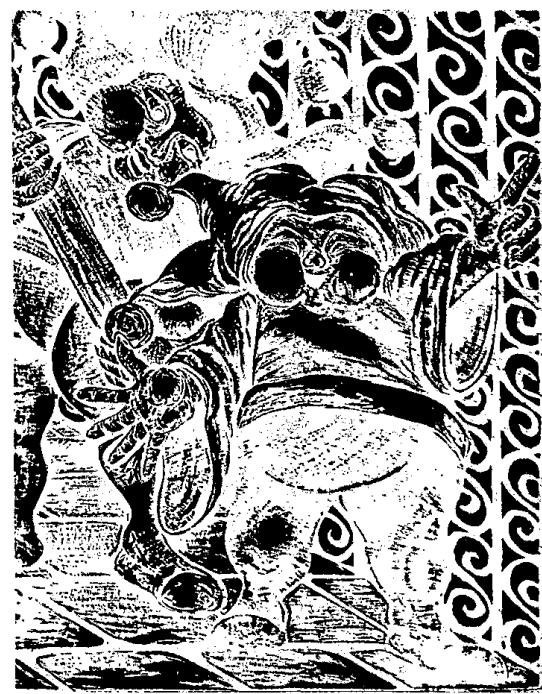

literarias extranjeras. Hoy se están publicando a un tiempo varias novelas, poesías, folletines de literatura, artículos de costumbres y estudios históri$\cos$, todo obra de jóvenes mexicanos, impulsados por el entusiasmo que cunde más cada día. ${ }^{9}$

Este fervor altamiraniano se reflejó en la aparición del periódico literario El Renacimiento, que él mismo fundó y se publicó a lo largo de 1869 . Dicha revista, abierta a los autores de "todas las edades y de todas las tendencias políticas", tuvo como fin reconciliar las posturas encontradas y formar una verdadera literatura nacional. En sus

9 Altamirano, "Revistas Literarias de México" $^{n}$ en Martínez, Literatura, 1949, vol. 1, p. 9. 
páginas encontramos artículos de Roa Bárcena, Vigil, García Cubas, Riva Palacio, Chavero, Olavarría y Ferrari y por supuesto de su director, Altamirano.

Es evidente que, aparte de pertenecer a las asociaciones culturales mencionadas, nuestros autores no pudieron desvincularse del acontecer político que los rodeaba. Fueron todos ellos hombres polifacéticos que vivieron su tiempo con gran intensidad y buscaron respuestas adecuadas a las situaciones que se les presentaban. Así, en tiempos de guerra, la mayoría había combatido a la intervención extranje$\mathrm{ra}$, ya fuese con las armas o con la pluma. Durante aquellos aciagos años se identificaron plenamente con la pléyade reformista, enarbolando con ésta las banderas de la Constitución de 1857 y de las Leyes de Reforma, como símbolos de la lucha contra la reacción y la invasión extranjera, símbolos que se convertirían después en el leitmotiv del partido liberal. Una vez terminada la guerra, el recuerdo de aquellas infaustas vivencias y el deseo de establecer una paz duradera llevaron a nuestros personajes a buscar la reconciliación nacional. Fue en esas circunstancias que la historiografía cobró para ellos un sentido vital. Todos compartieron una preocupación de orden político y moral al acercarse a la historia, y ante el gran reto que significó la reconstrucción del país, el quehacer historiográfico se convirtió en una tarea trascendental, buscando con ella reforzar el sentimiento de identidad nacional.

Para comprender la importancia que tuvo la historiografia para los autores que nos ocupan es preciso remon- tarse a 1867. La victoria de los liberales sobre la intervención extranjera y el partido conservador hizo que aquéllos se sintiesen los amos del devenir patrio. Ese sentir quedó plasmado en el discurso que el 16 de septiembre de ese año pronunció en Guanajuato, Gabino Barreda, presidente de la recién nombrada comisión que se encargaría de reformar la educación. En su Oración Cívica, Barreda sostuvo, por un lado, que el devenir histórico de México sólo podía explicarse dentro de la "evolución progresiva de la humanidad" $y$, por otro, que el único partido que podía considerarse como verdaderamente nacional era "el gran Partido Liberal". ${ }^{10}$ Lleno de orgullo, presentó a la guerra que acababa de terminar como el "conflicto entre el retroceso europeo y la civilización americana". Insistió en que "en esta lucha del principio monárquico contra el principio republicano, los republicanos de México se habían encontrado solos contra el orbe entero". ${ }^{11}$ La tenacidad de Benito Juárez y la valentía de aquellos liberales que habían sostenido sin interrupción el combate, seguidores de los principios de los héroes de la independencia, habían logrado finalmente la emancipación de México dando fin a la tarea que habían iniciado aquéllos. Siguiendo esta marcha evolutiva, recalcaba, la nueva hazaña había ido más allá que la de 1810 pues ahora se había logrado no sólo la emancipación política sino la religiosa. Una vez obtenida la victoria, se debía emprender la re-

${ }^{10}$ Barreda, Estudios, 1941, p. 103.

11 Ibid., p. 95. 
construcción social, misma que vendría en forma natural ya que el país reunía todos los elementos para ello. En efecto, según don Gabino, "todos los obstáculos se encuentran allanados; todas las fuerzas morales, intelectuales o políticas que deben concurrir con su cooperación, han surgido ya". ${ }^{12}$

Lo único que se debía hacer era conservar por algún tiempo "la paz y el orden", los cuales "harán por sí solos lo que resta" ${ }^{13}$ El optimismo expresado por Barreda era el de todos los liberales, y si bien su Oración cívica introdujo conceptos positivistas que, como bien nos dice Hale, entrarían después en contradicción con "mimados principios del liberalismo", ${ }^{14}$ es claro que este discurso marcó el principio de la versión oficialista de nuestra historia que culminó en la década de 1880 con México a través de los siglos.

Creemos que, desde el punto de vista de la historiografia, en 1867 se volvió a repetir en cierta manera lo que había sucedido en 1848. Si bien en aquel año la derrota y la pérdida de más de la mitad del territorio habían trastocado al país y en cambio en 1867 se había logrado vencer al invasor, en ambas ocasiones la intervención extranjera fue un acicate para la reafirmación del nacionalismo. Entonces como ahora se hizo evidente que cabía insistir en aquello que hacía de México una nación. Se quiso mostrar que no sólo se compartía un ámbito geográfico común, sino también un

\footnotetext{
12 Ibid., p. 109.

${ }^{13}$ Loc. cit.

${ }^{14}$ Hale, Transformación, 1991, p. 24.
}

pasado histórico y unas tradiciones culturales de las que se tenía que estar orgulloso. Se hizo un esfuerzo magno para dar a conocer la geografia de nuestro país, para retratar paisajes, rehabilitar costumbres, tipos populares, etc. ${ }^{15} \mathrm{~A}$ la vez, el rescate de nuestro devenir histórico se convirtió en una labor de primera importancia, buscándose un discurso que articulase el pasado en su conjunto y diese sentido al presente. En pocas palabras, se estaba en busca de un discurso integrador de la nación.

\section{LOS DISTINTOS GÉNEROS HISTORIOGRÁFICOS}

La labor emprendida por nuestros autores tuvo varias facetas, algunas de ellas difícilmente aceptadas hoy en día como historiografia. Sin embargo, cabe recordar que en el momento en que escribieron el campo de acción literaria abarcaba un espectro mucho más amplio. Así, unos se dedicaron al género histórico monográfico, otros al biográfico, otros más a la compilación documental y a las obras eruditas, algunos a la historia general de México, algu-

15 No fue por casualidad que en los años que siguieron a la guerra con Estados Unidos se editasen obras que tenían como fin dar a conocer las características propias del país. Así, en 1853 se publicó Los mexicanos pintados por sí mismos, libro que describía los tipos peculiares de la vida mexicana al mediar el siglo. Aquel mismo año empezó a publicarse por entregas el Diccionario universal de historia y de geografía con su Apéndice que tenía sólo información sobre México. Entre 1855 y 1856 apareció México y sus alrededores, excelente colección de vistas, trajes y monumentos mexicanos. 
nos más a los libros de texto y otros cuantos a la novela histórica, dándose el caso de que varios de ellos incursionaran en dos o tres de estos géneros a la vez. Así, García Icazbalceta, Arias, Roa Bárcena, Vigil, García Cubas, Castillo Negrete, Riva Palacio, Altamirano, Paz, Rivera Cambas, Chavero, Olavarría y Zárate se dedicaron a escribir monografias, biografias o historia general de México. El mismo García Icazbalceta, Hernández y Dávalos, García Cubas, Castillo Negrete, Paz, Romero, Rivera Cambas y Chavero se consagraron a la recopilación de documentos y a obras eruditas. Roa Bárcena, García Cubas, Rivera Cambas y Zárate se aplicaron también a los libros de texto y, finalmente, Riva Palacio, Altamirano y Olavarría junto con Mateos y Paz se ocuparon de transmitir el conocimiento histórico a través de novelas. En las siguientes páginas tratamos de dar una visión panorámica del campo historiográfico en que incursionaron nuestros autores, aclarando de antemano que, por razones de espacio, sólo apuntamos aquellas obras que nos parecen más significativas.

\section{Las obras históricas monográficas}

Durante los primeros años que siguieron al triunfo sobre el imperio de Maximiliano, una parte importante de la producción historiográfica giró en torno a los acontecimientos que acababan de suceder. Se escribieron entonces sendos artículos y algunos libros que tuvieron como objeto, por un lado, reseñar los hechos de armas que habían logrado el triunfo de las fuerzas republicanas, y por otro, defender a
México de la campaña denigrante que se había orquestado en Europa a raíz del fusilamiento de Maximiliano. Por ello, no acababa aún 1867 cuando Juan de Dios Arias publicó su Reseña histórica de la formación y operaciones del cuerpo del ejército del Norte durante la intervención francesa, sitio de Querétaroy noticias oficiales sobre la captura de Maximiliano, su proceso íntegro y muerte, en la que mostró que las heridas estaban todavía muy frescas. En el mismo año, José María Vigil escribió un folleto al que llamó Vindicación del pueblo mexicano en la invasión francesa de 1862, título que hablaba por sí solo. En 1874 el propio Vigil colaboró con Juan B. Hijar y Haro en el Ensayo histórico del Ejército de Occidente, en el que presentaron las hazañas bélicas en aquella región durante la guerra contra el francés. En 1884, bajo el título $\mathrm{Al}$ gunas campañas, Ireneo Paz publicó sus memorias, en las que refirió tanto las acciones militares en las que participó durante la intervención francesa como su militancia en las distintas revueltas contra el orden establecido a raíz de la restauración de la república. Para 1888, Manuel Rivera Cambas empezó a publicar, en forma de folletos, la que sería su voluminosa Historia de la intervención europea y norteamericana en México y del imperio de Maximiliano de Habsburgo, en la que, de manera un tanto desorganizada pero con gran sustento documental, presentó como hilo conductor de nuestra historia decimonónica la lucha entre las ideas monárquica y republicana y la interacción de los intereses de las potencias extranjeras. 
A la vez que algunos autores historiaban el pasado inmediato, otros prefirieron echar una mirada retrospectiva a hechos más lejanos con el fin de explicarse los acontecimientos vividos y tratar de evitar una repetición de lo acontecido. Así, mientras Altamirano se propuso revisar el devenir histórico de nuestro país durante el siglo XIX, Roa Bárcena tuvo interés en rescatar su visión de la guerra del 47 . Fue entre 1879 y 1882 cuando don José María escribió una serie de artículos sueltos que llamó Recuerdos de la invasión norteamericana por un joven de entonces, 1846-1848 que, en 1883, tomó forma de libro. En cuanto a Ignacio Manuel Altamirano, en 1883 vio la luz en Nueva York su estudio titulado Revista histórica y política, donde explicaba el devenir histórico de México de 1821 a 1882, presentándolo como una lucha entre la democracia y la oligarquía, en la que habian tenido una importancia determinante las grandes figuras heroicas.

\section{El género biográfico}

Fue también a partir de 1867 que varios autores de la generación tuxtepecana realizaron -o colaboraron enobras cuyo sentido fue dar a conocer las figuras más prominentes de nuestra historia, recurriendo a los relatos heroicos con fines eminentemente didácticos y moralistas. Así, entre 1870 y 1871 Vicente Riva Palacio, Juan A. Mateos y Rafael Martínez de la Torre publicaron, junto con Manuel Payno, El libro rojo obra que, si bien llevaba un subtítulo muy truculento, Hogueras, horcas, patíbulos, martirios, sui- cidios y sucesos lúgubres y extraños acaecidos en México durante sus guerras civiles y extranjeras, tenía como fin último recordar a aquellos personajes sacrificados por la nación. Paradójicamente, la lista empezaba con Moctezuma y terminaba con Maximiliano. La función edificante de la obra se hizo evidente cuando Riva Palacio expresó que "la sangre de los mártires fecunda la tierra; el que muere por su patria es un escogido de la humanidad, su memoria es un faro, perece como hombre y vive como ejemplo". 16 Por otro lado, se trataba de expiar las culpas de "la patria", tal y como lo dejó asentado Mateos:

El libro ensangrentado de nuestra historia es uno de aquellos monumentos terribles donde se ve la expiación y el castigo que deja caer la mano vengadora de Dios sobre los pueblos a quienes azota la guerra fratricida. ${ }^{17}$

En cuanto a los últimos artículos, tuvieron un eminente tono conciliador tal y como lo vemos en las siguientes expresiones de Martínez de la Torre:

Patria, patria infortunada y querida: si de los votos de estas víctimas dependiera tu felicidad, la unión de tus hijos te abriría el más brillante porvenir, y México sería grande y feliz con la unión de los mexicanos.

Ojalá y la generación que ha asistido al drama sangriento de las disensiones por la patria, sea también la que abra

${ }^{16}$ Riva Palacio et al., El libro rojo, 1988, vol, II, p. 223.

17 Ibid., vol. III, p. 313. 
por la fraternidad y la conciliación, una nueva vida en el suelo privilegiado de la República.

No había pasado un año cuando, en 1872, Manuel Rivera Cambas empezó a publicar Los gobernantes de México. Galería de biografías y retratos de virreyes, emperadores, presidentes $y$ otros gobernantes que ha teni. do México desde Hernán Cortés hasta el C. Benito Juárez. A diferencia de El libro rojo, que se había ocupado tanto de personajes prehispánicos como de los tiempos posteriores, Rivera omitía a los primeros. Sus biografias fueron mucho más escuetas y, desde luego, menos trágicas. Don Manuel dio asimismo gran importancia a las imágenes, por lo que ilustró a sus biografias con los retratos de los caudillos. Su objetivo fue bien claro al decir que su intención era "generalizar los conocimientos históricos sobre nuestra patria". ${ }^{18}$

En 1873 se publicó la obra Hombres ilustres mexicanos. Biografia de los personajes notables desde antes de la conquista hasta nuestros días. La mayoría de sus autores perteneció a la generación tuxtepecana, entre ellos varios historiadores de provincia como Agustín González, Emilio Velasco y Eufemio Mendoza, y otros tantos como Altamirano, Chavero, Vigil y Zárate fueron del grupo de los $17 \mathrm{hom}$ bres de letras que nos ocupa. La idea del editor de la obra, Eduardo Gallo, fue también "prestar un servicio a la

18 Rivera Cambas, Gobernantes, prólogo, $1872-1873$. historia nacional". Los colaboradores le ofrecieron "ayudar a mitigar los males que está causando el egoísmo, gangrena de las sociedades modernas", ${ }^{19}$ refiriéndose seguramente a la necesidad de conciliación. Afirmaron, además, que acometían la empresa con entusiasmo pues el catálogo de hombres ilustres era "inmenso para gloria de nuestra patria". ${ }^{20}$ Nos llama la atención que esta obra, en su primer tomo, se dedique a las biografias de los reyes aztecas, mientras que en los tres restantes retrata más bien a personajes que destacaron en el campo de la cultura. Sea lo que fuere, su objetivo era "encadenar los sucesos de tal manera que nuestra obra pueda ser la historia de México, comenzando desde los tiempos en que la verdad histórica se confunde con la fábula y los acontecimientos comprobados con los que narra la leyenda" ${ }^{21}$ Ello nos muestra cómo se tenía ya en mente la idea de escribir una historia de México que abarcase desde antes de la conquista hasta los tiempos actuales. No está de más señalar que tres de los autores de estas biografias, Chavero, Záratey Vigil, colaboraron al cabo de una década en México a través de los siglos.

Entre 1877 y 1880 , Emilio del Castillo Negrete publicó Galería de oradores de México en el siglo XIX, obra en la que reprodujo partes de los que él consideró los mejores discursos, "modelos dignos de ser imitados", de la

\footnotetext{
${ }^{19}$ Altamirano et al., Hombres, 1873, vol. 1, p. 5 .

${ }^{20}$ Ibid., vol. 1, p. 6.

21 Loc. cit.
} 


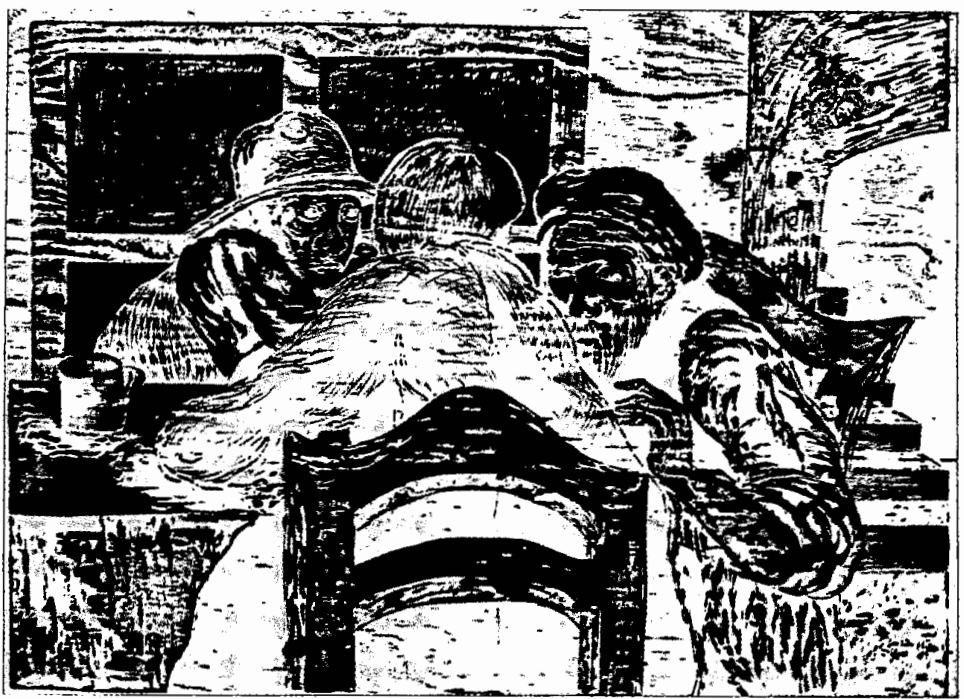

"pléyade de oradores que han entiquecido nuestras ciencias, nuestra literatura", ${ }^{22}$ con algunos datos biográficos de cada uno de ellos. Con este mismo propósito de rendir homenaje a las grandes figuras mexicanas, en esta ocasión las de sus contemporáneos, Riva Palacio escribió en 1882, bajo el pseudónimo de Cero, la obra Los Ceros, galería de contemporáneos. En ella hizo aparecer a algunos de ellos al lado de reconocidos hombres ilustres de la historia universal, resaltando a través de este paralelismo el papel desempeñado por estas figuras nacionales. IX.

22 Castillo Negrete, Galeria, 1877-1880, p.
Las compilaciones documentales $y$ las obras eruditas

Es evidente que la búsqueda y compilación de documentos no se inició con la generación tuxtepecana; sin embargo varios de sus más destacados integrantes se dedicaron a ella en cuerpo y alma. Éstos consideraron dicha tarea como indispensable para que algún día se escribiese la historia de nuestro país con plena veracidad. Así, la pauta dada por José Fernando Ramírez y Manuel Orozco y Berra, miembros ambos de la pléyade de la Reforma que se dedicaron a rescatar documentos del México prehispánico y colonial, fue seguida por Joaquín García Icazbalceta y Alfredo Chavero. Don Joaquín, que desde joven había colaborado con los 
autores arriba mencionados, publicó en 1886 su famosa Bibliografía mexicana del siglo XVI, y aquel mismo año empezó a salir su Nueva colección de documentos inéditos para la historia de México, misma que venía a completar la que había publicado entre 1858 y 1866. Alfredo Chavero, a su vez, se dedicó a reeditar obras del México colonial de tradición indígena, con notas y apéndices que ayudaran a su comprensión.

Por su lado, Matías Romero tuvo siempre interés en dejar testimonio, por medio de la compilación de documentos, de los acontecimientos de los que había sido testigo y actor, con el fin de dejar huellas fehacientes para la futura historiografia. La obra más importante y meticulosa que compiló don Matías consistió en los diez voluminosos tomos que conforman la $\mathrm{Co}$ rrespondencia de la legación mexicana en Washington durante la intervención extranjera, 1860-1868, que empezó a publicar en 1870 . A la vez que Romero trabajaba en la edición de los materiales que servirían para escribir la historia inmediata, Juan Evaristo Hernández y Dávalos se preocupó por recopilar cuanto documento existía sobre la guerra de Independencia. Así, entre 1878 y 1882 publicó, por entregas, su invaluable Colección de documentos para la guerra de Independencia de México, que abarcó sólo seis tomos de los 18 que don Evaristo había compilado.

Junto con la labor desarrollada por estos grandes recopiladores de documentos, hay que mencionar a Antonio García Cubas y a Emilio del Castillo Negrete, que fueron los autores de una serie de obras eruditas que contribuyeron a la difusión del conocimiento histórico sobre nuestro país. Así, don Emilio empezó a publicar en 1875 su obra México en el siglo XIX, cuyo sentido era reseñar, con base en un gran número de documentos, los principales acontecimientos ocurridos en nuestro país durante aquel siglo pero que, debido a su muerte, sólo llegó hasta la firma de los Tratados de GuadalupeHidalgo. Esta obra monumental constó finalmente de 25 volúmenes y varios apéndices.

En cuanto a la labor desarrollada por García Cubas en el quehacer historiográfico, debemos reconocer que si bien destacó más como geógrafo, don Antonio fue el autor de una serie de obras propagandísticas sobre México que tuvieron como fin difundir una imagen positiva de nuestro país y que incluyeron todas ellas su parte historiográfica. Entre 1876 y 1893 , don Antonio publicó cinco obras de este género. La primera fue The Republic of Mexico in 1876, a Political and EthnographicalDivision of the Population, Character, Costumes and Vocations of its Inhabitants. Las otras cuatro, casi idénticas entre sí, fueron publicadas por la Secretaria de Fomento en distintos años y diferentes idiomas. Así, en 1884 vio la luz el Cuadro geográfico, estadístico, descriptivo e histórico de los Estados Unidos Mexica. nos, título que volvió a repetirse en 1885 con el subtítulo de "Obra que sirve de texto al Atlas pintoresco de Antonio García Cubas". En 1889 la obra salió a la luz en francés: Étude géographique, statistique, déscriptif et historique des Etats Unis Mexi- 
cains, obra que en 1893 se tradujo al inglés: Mexico, its trade, industries and resources. 23

También se debió a este afán de difundir una nueva imagen de nuestro país tanto entre sus habitantes como en el extranjero el que, entre 1880 y 1883, Manuel Rivera Cambas publicara su obra México pintoresco, artístico y monumental, en la que incluyó bellas litografias. He aquí su razón de ser:

Corresponde a nuestra época rectificar los escritos de multitud de viajeros que, con precipitación y juzgando de nuestras cosas a primera vista, han asentado crasísimos errores y desviado la opinión en el extranjero y aun entre nosotros mismos, acerca de nuestra civilización y de nuestro adelanto. ${ }^{24}$

Es evidente que la obra de don Manuel fue mucho más lejos de lo que modestamente dejó asentado. Con el mismo sentido propagandístico, Ireneo Paz publicó en 1888 su libro Loshombres prominentes de México, en el que se propuso dar "a conocer a los hombres y levantar tan alto como debe estar el nombre de México, cuyo fértil suelo se encuentra quizá destinado en el porvenir a encerrar una de las más grandes y más prósperas naciones". ${ }^{25}$ En ella presentaba, en edición

${ }^{23}$ Para mayor detalle sobre el contenido histórico de esta tetralogía véase Carmen Collado, "Antonio García Cubas", en Rosa Camelo (coord.), Historiografía Mexicana, vol. IV (en prensa). 515.

${ }^{24}$ Rivera Cambas, México, 1974, vol. I; p.

${ }^{25}$ Paz, Hombres..., prólogo, 1888. trilingüe, las biografras de más de cien de sus contemporáneos.

Finalmente, en lo que a las obras eruditas se refiere, debemos mencionar que entre 1888 y 1898 García Cubas publicó su Diccionario geográfico, histórico y biográfico de los Estados Unidos Mexicanos, obra enciclopédica colectiva que constó de cinco tomos y que representó, en cierta manera, la culminación de la tarea iniciada entre 1853 y 1856 por los redactores del Diccionario universal de historia $y$ de geografía, cuyo último afán consistió en elaborar un diccionario exclusivamente mexicano.

\section{La historia general de México}

Por lo reseñado hasta ahora podemos ver cómo la generación tuxtepecana se esmeró por crear una conciencia nacional que estuviese orgullosa de su pasado y confiada en su porvenir. A pesar de sus esfuerzos, fue sin embargo hasta la década de los ochenta cuando, al triunfo de la rebelión de Porfirio Díaz, la labor de conciliación fue ganando terreno. La tranquilidady los beneficios materiales palpables como fueron la construcción de vías férreas, el telégrafo y los avances de la ciencia, desarrollaron la confianza e hicieron que se creyese sinceramente que el país advenía finalmente a la senda de la paz y del progreso. No fue pues casualidad que los intentos de escribir una historia general de nuestro país fructificasen hasta aquellos años.

Cabe recordar que el primer proyecto de esta historia general se había presentado en 1862. En aquel año, 
Francisco Carbajal Espinoza expuso, en el seno de la Sociedad de Geografía y Estadística, su plan para redactar una Historia de México desde los primeros tiempos de que hay noticia hasta mediados del siglo XIX. Don Francisco sólo publicó dos volúmenes, uno dedicado al México precolombino y otro a la conquista española hasta 1521. En 1865, en medio de las luchas fratricidas que provocaron la intervención francesa y el establecimiento del imperio de Maximiliano, Manuel Larrainzar propuso, en el seno de la misma asociación científica, un plan para escribir la historia general de México en una serie de conferencias que tituló Algunas ideas sobre la historia y manera de escribir la de México. ${ }^{26}$ Debido a los tiempos que corrían, la propuesta tampoco prosperó.

En 1869, Ignacio Manuel Altamirano celebró con entusiasmo la decisión de Manuel Orozco y Berra de impartir unos cursos de historia general de México, comentando:

Nosotros quisiéramos que un triple número de los discípulos actuales asistieran a estas sabias lecciones que, no lo dudamos, van a tener una gran trascendencia en nuestra literatura histórica. [...] Hay algo más para los jóvenes estudiosos de México que hacer versitos y novelas. Hay la historia, que nos brinda sus ricos tesoros desconocidos y que cuando se exploten enriquecerán al mundo, como lo han enriquecido los metales de nuestras minas. ${ }^{27}$

${ }^{26}$ M. Larrainzar, "Algunas ideas sobre la historia y manera de escribir la de Mêxico", en Ortega y Medina, Polemicas, pp. 133-255.

27 "Crónica de la Semana", El Renacimiento, 27 febrero 1869.
El curso de don Manuel abarcaba tres etapas: la antigua, que concluía con la conquista de México, la media, que terminaba en 1821, y la moderna, que llegaba hasta los tiempos contemporáneos, siguiendo en esto los lineamientos indicados por Larrainzar en 1865. No sabemos si el curso prosperó y es una lástima que dicha historia no haya tenido mayor difusión.

Entre 1875 y 1877 , el zacatecano Ignacio Álvarez publicó en su ciudad natal sus Estudios sobre la historia general de México. Ésta fue la primera vez que se llevó a cabo, de manera completa, la empresa que se había considerado tan necesaria desde tiempo atrás, de hecho desde la publicación del $D i c$ cionario universal de historia y de geografía en 1853-1856. La división temática emprendida por Álvarez fue la misma que luego siguieron Niceto de Zamacois y los autores de México a través de los siglos: la historia antigua, la conquista, el gobierno virreinal, la guerra de Independencia, los gobiernos del México independiente y la Reforma y el Imperio. Al escribirla, don Ignacio dejó asentado que lo hacía por patriotismo, pues "nunca puede amarse debidamente un objeto desconocido: y será tanto mayor el amor que se le tenga, cuanto más se conozcan sus glorias y sus desventuras". ${ }^{28} \mathrm{La}$ obra resultó ser un discurso ultramontano que acusaba a los liberales de ser los causantes de todos los males de México.

Cuando el escritor zacatecano se hallaba escribiendo su obra, Zamacois

${ }^{28}$ Álvarez, Estudios, 1875-1877, vol. 1 p. II. 


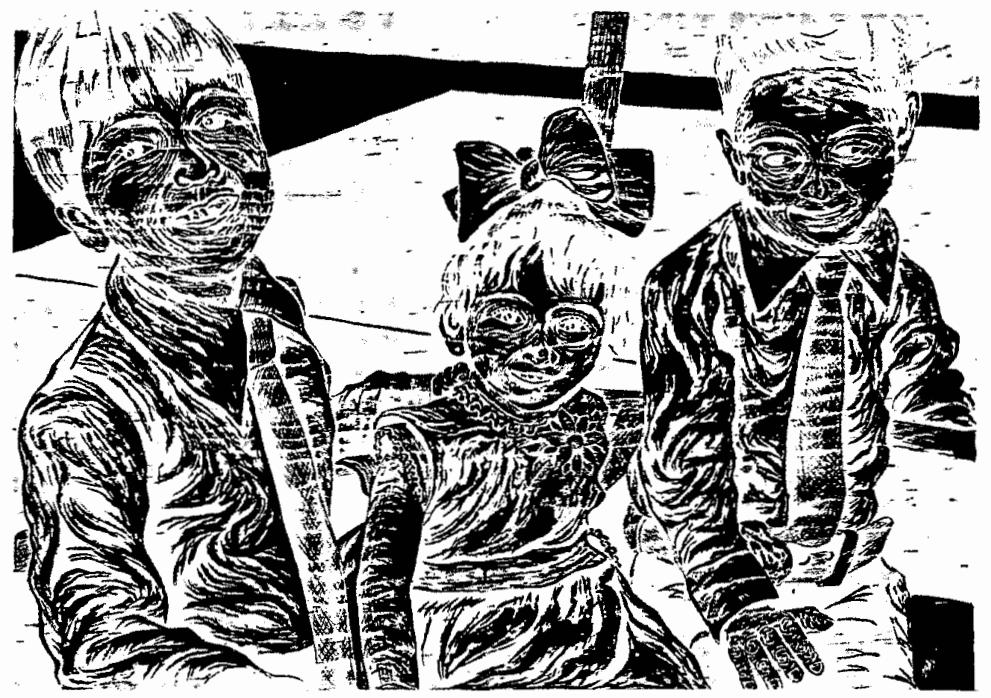

empezaba en Madrid su Historia de Méjico, editada entre 1876 y 1882 . En ella el escritor español, siguiendo la misma división temática séñalada por Larrainzar, brindaba también una visión conservadora de nuestro devenir histórico, pero a diferencia de Álvarez no sólo con un afán conciliador sino con un análisis mucho más objetivo. Es evidente que a don Niceto le preocupaba la ruptura de la sociedad mexicana, ruptura que a su parecer la había desviado del camino del progreso y de la modernidad. Por ello fue que con su discurso integrador llamaba a la concordia entre todos los mexicanos.

Entre 1880 y 1886 el estadunidense Hubert H. Bancroft publicó, en San Francisco, California, su History of Mexico en seis tomos. Este nuevo dis- curso histórico sobre nuestro país tuvo motivaciones distintas de las del escritor español. Bancroft se interesó en México por dos razones; primero porque era uno más de los estados que se encontraban en la zona del Pacífico norte, área que la "fábrica de hacer historia" bancroftiana se había propuesto estudiar; segundo, porque quería mostrar el progreso que nuestro país había logrado bajo la égida porfirista, invitando a los inversionistas estadunidenses.

Es evidente que ninguna de estas obras cumplía los requisitos para servir como historia general de un país que acababa de triunfar sobre la reacción mexicana y los extranjeros. Cuando finalmente había llegado la paz y se creía estar en la vía de la prosperi- 
dad, correspondía a los liberales triunfantes escribir su propia versión del tan esperado discurso integrador. Éste tenía que articular.el pasado, dar sentido al presente y ofrecer un proyecto para el futuro. La Oración cívica proclamada por Gabino Barreda en 1867 serviria ahora de pauta, ya que sería la concepción progresista de la historia la que permitiría la elaboración de tal discurso. La idea de continuidad y no la de ruptura, inspiraría el título mismo de México a través de los siglos, excelente ejemplo de la visión esencialista de la nación.

Se concibió entonces al ser nacional como la suma y no como la contraposición de sus dos pasados. La conquista habia sido un paso dolorosísimo pero inevitable dentro del lento pero permanente progreso humano. Se presentó a la nación como la heredera de una doble tradición, la indígena y la colonial, manejando el mestizaje como el elemento conformador de la identidad nacional. Esta mezcla de razas debía ser razón de orgullo y no de vilipendio, tal y como lo había dejado asentado en 1878 Josê María Vigil y como lo afirmaba Vicente Riva Palacio, coordinador de la magna obra:

Con tan extraños elementos formóse en el siglo Xvi el embrión de un pueblo que con el transcurso de los años debía ser una República Independiente.

Laboriosa y dificil evolución tenía que consumar aquel informe agrupamiento de familias, de pueblos y de razas, unidos repentinamente y al azar por un cataclismo social y político, para organizarse, cohonestando sus tendencias y esfuerzo, y construir la sociedad de donde debía surgir un pueblo que ni era el conquistado ni el conquistador pero que de ambos heredaba virtudes y vicios, glorias y tradiciones, caracteres y temperamentos. ${ }^{29}$

\section{Los libros de texto}

Al restaurarse la república en 1867 , se pensó en la necesidad de una mayor intervención del Estado en la educación para reforzar la ideología liberal. En lo que respecta a esta especialidad, la Ley Orgánica de Instrucción Pública del 2 de diciembre de 1867 estableció definitivamente la enseñanza de la historia de México a nivel primaria, y al cabo de un año dicha materia se convirtió también en obligatoria en la recién fundada Escuela Nacional Preparatoria. ${ }^{30} \mathrm{Si}$ bien en esta institución la historia nacional tendría una trayectoria azarosa, ya no desaparecería de los planes de estudio de primaria. Al haber separado a la Iglesia del Estado y suprimido la enseñanza religiosa en todos los niveles de la educación pública, se necesitaba otro sustento ideológico. Se trataba de crear un nuevo carácter nacional, laico, que modificase los hábitos mentales, las costum. bres y aun los valores de los mexicanos. La educación, dirigida por el Estado, moldearía la conciencia colectiva del país. Los relatos históricos, moralizantes y edificantes para la juventud, jugarian ahora el papel que antes habían tenido los religiosos. La

29 V. Riva Palacio, "El virreinato" en Riva Palacio et al.; México,1980, vol. 3, p. VIII.

${ }^{30}$ Dublán y Lozano, Legislación, 1876-1904, vol. X, pp. 193-205; Meneses Morales, Tendencias, 1983, pp. 167-176, 204-208. 
historia sería la vía para lograr dicho cambio y se convertiría en el vínculo de identidad nacional.

Sería a través de la historia patria, término acuñado en estas décadas, que los educandos conocerían su herencia y reverenciarian a sus héroes, quienes asumirían así el lugar del santoral. Al decir de Guillermo Prieto, que si bien perteneció a la pléyade de la Reforma sobrevivió a sus contemporáneos y escribió sus Lecciones de historia patria en 1886, sólo a través del quehacer de Clío se podía exaltar el amor a la patria y enaltecer a sus hombres eminentes por sus virtudes. ${ }^{31}$ Fidel abría así las puertas de la historia de bronce de corte oficialista.

Aunque, en números, la contribución de la elite tuxtepecana a la elaboración de libros de texto no fue muy grande, ya que en el periodo que nos ocupa sólo cuatro de nuestros autores se abocaron al género didáctico, cabe señalar que las reediciones de estas obras hicieron que su presencia en el medio escolar fuese constante. Si bien el primer libro de texto escrito por un miembro del grupo no se ubica dentro de los años que nos hemos puesto como límite, no podemos dejar de mencionar que, en 1862, José María Roa Bárcena escribió su Catecismo elemental de historia de México, obra que se reeditó cinco veces entre 1867 y 1888. En 1873 Manuel Rivera Cambas escribió su Cartilla de la historia de México para uso de las escuelas de la República, dividido en tres cuadernos, de la que se hicieron luego nue-

31 Prieto, Lecciones, 1986, p. 464. ve ediciones. En 1884 Julio Zárate sacó a la luz su Compendio de historia general de México, del que se hicieron seis reediciones. Finalmente, en 1890, Antonio García Cubas contribuyó también al conocimiento histórico de nuestra juventud con su Compendio de historia de México y de su civilización, del que se hicieron tres reediciones. Cabe señalar que tanto Zárate como García Cubas escribieron en la década de 1890 nuevos textos de historia patria, a lo cuales no nos referimos por caer en fechas fuera de nuestro estudio. ${ }^{32}$

\section{La novela histórica}

No es nuestra intención repetir lo que se ha dicho sobre el impulso que dio Ignacio Manuel Altamirano a la novela histórica de tema mexicano. Basta sólo recordar que se la consideró como el medio más idóneo para difundir los conocimientos históricos por medio de impresos baratos y de lectura fácil, y totalmente válida y objetiva desde el punto de vista historiográfico. Excelentes trabajos se han ocupado del género novelístico de Ignacio Manuel Altamirano, Vicente Riva Palacio, Juan A. Mateos y Enrique Olavarría y Ferrari. ${ }^{33}$ Sin embargo, el caso de Ireneo Paz ha sido poco estudiado. De acuerdo con los postulados altamiranianos de que la novela era el mejor vehículo para conformar una cultura histórica que reafirmase el patriotismo, Paz es-

32 Véase Roldán, Conciencia, 1995.

33 De estas novelas se han ocupado en diver. sos estudios José Ortiz Monasterio, Clementina Díaz y de Ovando y Álvaro Matute. 
cribió, entre 1873 y 1914 , quince novelas o leyendas -como él las llamóhistóricas. ${ }^{34}$

A pesar de que varias veces don Ireneo señaló que no se proponía "más que unas obritas recreativas", le interesó aclarar que su intención era contribuir, "dentro de la órbita de sus facultades", a la difusión de los conocimientos históricos, "que no sólo sirven para vigorizar el ánimo con los recuerdos patrióticos, sino que forman asimismo la experiencia de las naciones". ${ }^{35}$ La idea de Paz era difundir la historia patria fuera del ámbito académico y hacerla llegar a aquellas personas que "se fatigan con la lectura de los libros serios", las que "no tienen tiempo de dedicarse al estudio", las que "por carácter gustan más de los escritos recreativos", las que aun conociendo bien los hechos "quieren refrescar su memoria" y, finalmente, "todas las que siguen con más interés una relación salpicada de diálogos y de variedad de incidentes que el árido libro del historiador sujeto a reglas especiales". 36 Su fin era también didáctico, pues quería

enseñarle al pueblo a formar su experiencia propia al presentarle de bulto los males que trajeron a nuestro país las imprevisiones, la desunión, el espíritu

${ }^{34}$ Los títulos de dichas leyendas son Amory suplicio, Doña Marina, El Lic. Verdad, La Corregidora, Hidalgo, Morelos, Mina, Guerrero, Antonio Rojas, Manuel Lozada, Su Alteza Serenisima, Maximiliano, Juárez!, Porfirio Díaz y Madero. Véase Vázquez Bravo, Alzado, 1992, y Pi-Suñer Llorens, "Ireneo Paz, divulgador...", en Garritz, Hombre, 1993, pp. 297-314.

$35 \mathrm{Paz}$, Maximiliano, 1899, p. 4.

${ }^{36}$ Loc. cit. de anarquía que nos dominaba y la falta de juicio que precedió a nuestra organización política. ${ }^{37}$

Si bien don Ireneo no se consideraba historiador sino que se presentaba como simple divulgador de la historia, debemos insistir en que tuvo interés en que sus relatos fuesen leídos como obras históricas. Por ello hizo hincapié en que sus datos eran fídedignos pues se basaban en fuentes veridicas. Insistió en que, a la vez que apegarse a la verdad, lo que le interesaba era dar a los hechos históricos "su fisonomía propia y caracterizar hasta donde sea posible a los actores del drama". Ello lo llevó al campo del relato novelesco y siguiendo a los historiadores románticos pretendió aproximarse al mundo intimo de los personajes, recreando las situaciones en que se encontraron. Aun cuando los presentó como hombres de carne y hueso, con sus penas y sus glorias, sus grandezas y sus debilidades, cayó en el relato heroico y, por ende, en la historia de bronce. Muy a tono con la historiografía monumental, y llevado por la necesidad de crear un panteón liberal, don Ireneo juzgó necesario enaltecer a los héroes y condenar a los antihéroes, lo que nos explicaría por qué los títulos de sus novelas correspondían a los próceres de nuestra historia.

\section{CONSIDERACIONES GENERALES}

Una vez revisados los distintos géneros historiográficos por los que incur-

37 Ibid. 
sionaron nuestros hombres de letras, nos interesa plantear algunas consideraciones generales respecto a lo que fue su quehacer.

\section{Influencias extranjeras}

Lamentablemente son pocas las referencias bibliográficas directas que hemos podido encontrar respecto a las obras que leían nuestros hombres de letras. Sin embargo hemos tratado de rastrear, tanto a través de sus propias citas como en los artículos publicados en los periódicos de mayor circulación, cuáles fueron sus lecturas y sus directrices historiográficas.

Lo que hemos podido comprobar es que por lo general estaban muy familiarizados con el ambiente cultural europeo y al corriente de las tendencias y metodologías que intentaban hacer de la historia un conocimiento de carácter científico. En cuanto a España, hemos hallado bastantes referencias al conde de Toreno, a Modesto Lafuente, Manuel José Quintana, Juan Valera, Emilio Castelar y Benito Pérez Galdós. En lo que respecta a la Gran Bretaña, hay referencias a Edmund Burke,'Herbert Spencer, Charles Darwin, John Stuart Mill y Henry Thomas Buckle. ${ }^{38}$ Sin embargo, lo que más nos ha llamado la atención han sido las lecturas francesas. Es evidente que desde el punto de vista cultural y de teoría política, todo lo que venía de Francia

\footnotetext{
38 Cabe señalar que por lo general las obras de estos ingleses fueron leídas en su versión francesa, tal y como lo vemos en el aparato crí tico de Vicente Riva Palacio en el tomo II de México a través de los siglos.
}

era bien recibido, por lo que la difusión de la literatura histórico-política fue muy importante. Si bien algunas obras fueron traducidas en México y otras llegaron en lengua castellana, tal parece que la mayoría fue leída en francés. Recordemos que, por lo general, nuestros intelectuales conocian bien dicho idioma y que ya desde décadas atrás el afrancesamiento cultural de nuestra elite era una constante, lo que explicaría por qué al mediar el siglo había cinco escuelas francesas en la ciudad de México. Esta comunión con Francia quedó plasmada en muchos de los escritos de las dos generaciones que combatieron la intervención francesa y que vieron estupefactas cómo las tropas de una nación que había servido de guía ideológica invadían a nuestro país. Así, en 1862 Manuel Payno preguntabaal general Forey cómo era posible que la nación que había esparcido la civilización por el mundo viniese a "destruir con los cañones las ideas que la misma Francia ha enseñado a las Américas". ${ }^{39}$ Por su parte, Rivera Cambas escribía en la década de 1880 que

muy lejos había estado el partido liberal mexicano de creer que llegaría a encontrarse frente a los franceses, de quienes había tomado aliento para llevar a cabo la lucha de tres años; ese partido se inspiró en libros franceses y había adoptado por guía y bandera los principios proclamados el año de 1789 , de los que sacó el vigor y la energía que le condujeron al triunfo. Al partido liberal se habían asociado los franceses residen-

39 Payno, Carta, 1862, p. 72 ; 


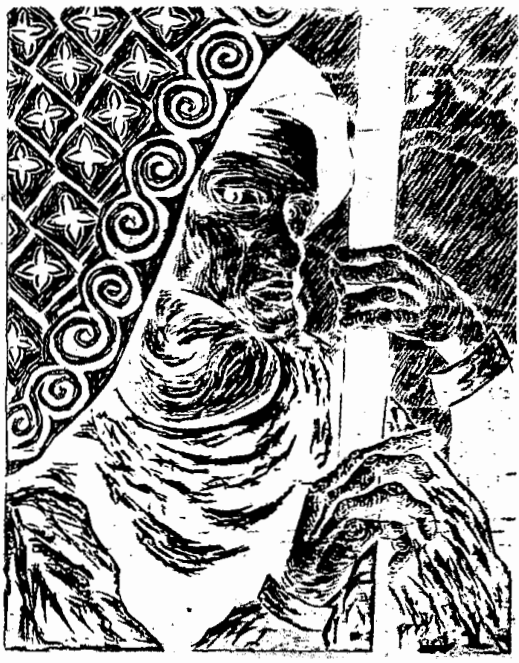

tes en México, y de tal manera se le habian identificado, que de la Francia esperaban el apoyo para realizar sus ensueños de libertad nacional y de conciencia, y la colonización e inmigración en el porvenir. [...] iExtraña anomalia la que se verificó al reunirse las fuerzas reaccionarias de Márquez con lo que proclamaban y habían extendido por todo el mundo los principios de Reforma y de Progreso! 40

A su vez, a dos años del triunfo de la república sobre la intervención y el imperio, Ignacio Manuel Altamirano hizo hincapié, en términos por demás 9.10.

${ }^{40}$ Rivera Cambas, Historia, 1987, vol. 11, pp. irónicos, en el afrancesamiento de la sociedad mexicana:

\begin{abstract}
México habrá podido combatir la intervención política de la Francia; pero será impotente para combatir la intervención moral. Vestimos a la francesa, comemos a la francesa, vivimos a la francesa, pensamos a la francesa. Trajes, peinados, joyas, alimentos, libros, música, bailes, todo lo debemos recibir de París. Nuestra sangre era americana antes; pero hoy con los filtros franceses parece también francesa. ${ }^{41}$
\end{abstract} tras galas no era desde luego nueva, ya que la mayoría de nuestros autores habían sido educados bajo los principios de la Ilustración, por lo que no nos ha extrañado hallar en ellos referencias a Montesquieu, Voltaire, Rousseau, Diderot, D'Alembert y Volney. En cuanto a los autores franceses del siglo XIX hemos encontrado unas veces citas $y$ otras sólo alusiones a obras como $E l$ genio del cristianismo, las Memorias de ultratumba y Estudios o discursos históricos sobre la caída del Imperio Romano, de Chateaubriand, La Historia de los girondinos y la Vida de los grandes hombres; de Lamartine, Cartas sobre la historia de Francia, de Thierry, la Historia de la revolución francesa, de Thiers, la Historia de la revolución francesa y la Historia de Francia de Michelet, la Historia de la república de Inglaterray de Cromwell y la Historia de Francia contada a mis nietos, de Guizot, Los orígenes de

41 "Crónica de la Semana", El Renacimiento, 3 julio 1869 .
Esta cercanía con la cultura y las le- 
la Francia contemporânea, de Taine, el Discurso sobre el espíritu positivo, de Comte, Historia de los Estados Unidos, de Laboulaye, Qué es una nación, de Renan. Asimismo, son varios los autores que hacen mención de la Revue des Deux Mondes, periódico que al parecer tuvo bastante circulación en México.

Creemos que muchas de estas obras fueron leídas más por interés político que historiográfico, por lo que no hemos podido sacar conclusiones generales acerca de la influencia que tuvieron en el discurso histórico de nuestros autores. Al no contar con un ensayo como Algunas ideas sobre la historia y manera de escribir la de México que Manuel Larráinzar escribió para la generación anterior, que nos permita profundizar en la teoria y filosofia de la historia en nuestro país en Ia época que nos ocupa, hemos tratado de sistematizar algunos aspectos que incumben al análisis historiográfico.

\section{La idea de la historia}

La constante que encontramos en las obras a que nos hemos referido es la idea del progreso. Por lo general nuestros autores estaban convencidos de que "la sociedad [...] en el orden natural no detiene su progreso". ${ }^{42}$ Para unos, este camino era inmanente a la humanidad, $y$ aun cuando pareciera que "todo progreso encuentra resistencias en las tradiciones del pasado, en esa fuerza de inercia que se quiere hacer venerable llamándola costum.

\2 García Cubas, Compendio, 1893, p. 239.

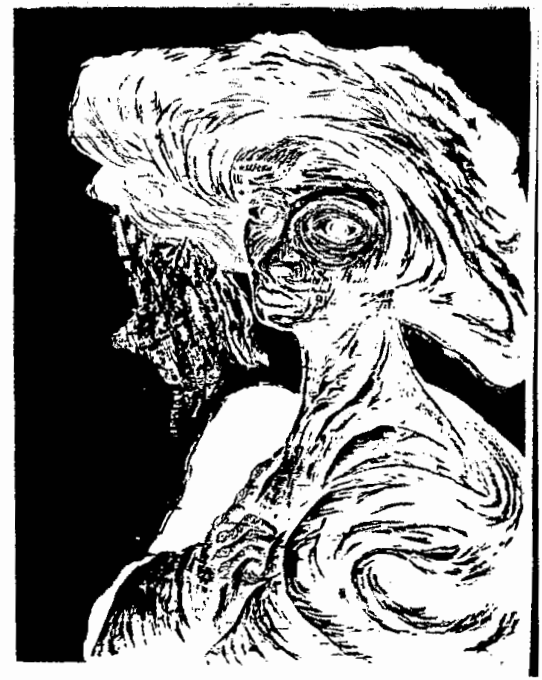

bre", como escribió Zarco, era ley de la historia que "lo nuevo triunfe de lo antiguo y que la costumbre cambie, se modifique y se perfeccione en un sentido progresivo". 43 El destino de la humanidad era, para don Francisco, el triunfo de la democracia. Para otros, como Altamirano, el progreso se fundaba en el respeto a la libertad, a la que consideraba como la fuerza motora de la sociedad, rechazando en cambio, toda clase de determinismos. En el mismo sentido, Riva Palacio sostenía que

la tendencia natural de los hombres a la libertad, la predisposición orgánica de

43 Zarco, "Las leyes y las costumbres. La federación y la libertad de cultos", El Siglo Diez $y$ nueve, 30 noviembre 1857 . 
los individuos, el ejemplo de otras naciones y el influjo del espíritu altamente progresista del siglo XIX inspiró $y$ alentó a la nación mexicana... ${ }^{44}$

A su vez, Juan de Dios Arias presentaba al proceso histórico mexicano como ejemplo del desenvolvimiento general de las naciones. Así, explicaba:

Acción y reacción, avance y retroceso, prosperidad y decadencia, desnivelamientos y esfuerzos, y luchas más o menos activas para llegar a un orden perfecto, constituyen el maravilloso panorama de las sociedades que nacen y crecen y se desarrollan a medida de propios o extraños elementos, o lógica de la naturaleza, sìn que jamás la necesidad o el acaso ciegamente y a guisa de cuñas de hierro, entren a separar o romper las cosas humanas. ${ }^{45}$

Sin embargo para algunos, los más influenciados por el romanticismo como sería el caso de Rivera Cambas, la fortuna o "el sino" eran factores importantes en el devenir histórico. Para otros más, había sido el cristianismo el que había echado "la simiente fecunda” de la civilización y del progreso, por lo que insistían en relacionar a la religión cristiana con los principios revolucionarios de libertad, igualdad y fraternidad. Para ellos, el mundo marchaba hacia la perfección guiado por la Providencia o por el "Artífice

44 Riva Palacio, "El virreinato", en Riva Palacio et al., México, 1980, vol. 4, p. 442.

${ }^{45}$ Juan de Dios Arias, "México independiente", en Riva Palacio et al., México, 1980, vol. 7 , p. III.
Divino", quien asignaba a cada hombre su misión o actuaba, por medio de leyes, en las fuerzas de la naturaleza. Así, Emilio del Castillo Negrete escribía que la humanidad

tiene trazada por la Providencia una misión que cumplir, y una obligación que llenar, y para llevarla a efecto arrollará a los tiranos y se abrirá paso por entre la sangre, el hierro y el fuego. El progreso y la libertad marchan a su perfección, lo contrario sería despojar a la Providencia de su más bello atributo, el de guiar al hombre por el sendero de la perfectibilidad [...] El mundo marcha y el que se oponga, será aplastado. ${ }^{46}$

Rivera Cambas, a pesar de creer en la existencia de la fortuna no titubeó en afirmar, en una de sus obras, que su intención era ocuparse de "los hombres de que se valió la Providencia para cumplir sus designios". ${ }^{47} \mathrm{Al}$ respec. to cabe recordar que el propio Guizot, seguramente el autor más citado por nuestros historiadores, asentó que "Ios hombres, a los que Dios toma por instrumentos de sus grandes designios, están llenos de contradicción y de misterio". ${ }^{88}$ Así, si bien las explicaciones primeras debian buscarse en las acciones -y las pasiones- humanas, en última instancia se recurría a una explicación de tipo providencialista.

A pesar de estas distintas posturas, creemos poder afirmar que, por lo general, la historia fue concebida como

46 Castillo Negrete, México, 1875-1892, vol. 1, p. 216.

${ }^{47}$ Rivera Cambas, Gobernantes, prólogo, 1872.

${ }^{48}$ Guizot, Histoire, 1854, p. 4. 
una larga y ardua marcha hacia el progreso y la modernidad en un sentido ascendente, acompañada a veces por cambios violentos o revolucionarios y en la que cada etapa se presentaba como superior a la anterior. Este proceso lineal de la historia, en que los grandes hombres tenían un papel de primerísima importancia, parecería a veces sustentarse en un determinismo con resabios providencialistas. Si bien varios de nuestros autores, como Zárate, Arias o Riva Palacio, utilizaron la terminología evolucionista, nos inclinamos a atribuirlo al ambiente intelectual predominante en el momento. Por ello no estaríamos de acuerdo en Ilamarlos positivistas, ya que no siguieron a esa filosofia en su interpretación del devenir histórico, tal y como sí lo hicieron los miembros de la generación posterior.

\section{El historiador y la historiografía}

Es evidente que la mayor parte de nuestros autores fue seducida por el método científico como la vía indiscutible para la recuperación del pasado. El rigor metodológico heredado del cientificismo ilustrado, así como la influencia de los historiógrafos franceses -recordemos el interés de Guizot por la publicación de "documentos inéditos"-y de la escuela erudita alemana, hicieron que nuestros personajes se obsesionaran con la idea de que el historiador debía ser totalmente imparcial y sólo atenerse a los documentos. Así, Castillo Negrete afirmaba:

Uno de los caracteres esenciales de todo historiador es la imparcialidad en lo que escribe: si carece de esta cualidad, no merece ciertamente ese título, y sus trabajos todo serán menos históricos, a no ser que se le considere como simple narrador o cronista [...] En su alto carácter de maestro y de juez severo e imparcial, tiene el estricto deber de apreciar en todos sus detalles, de examinar en todas sus relaciones y de indagar con toda precisión las causas que determinaron aquel acontecimiento y la influencia que sus consecuencias ejercieron. 49

Como lo verdadero debía ser comprobable, algunos de ellos añadieron a sus obras sendos apéndices documentales que corroboraban lo expuesto en su explicación histórica mientras que otros se afanaron por rendir cuentas de las fuentes de que habian bebido. Así fue como las referencias bibliográficas a pie de página se convirtieron para éstos en algo esencial.

Si bien es cierto que la búsqueda de la verdad fue un propósito que desde la antiguedad clásica había movido a los historiadores, nos atreveríamos a afirmar que, con los lineamientos metodológicos de la historiografia erudita, esta premisa se volvió casi una obsesión. Por ello, la aseveración de Riva Palacio en cuanto a que "el historiador no puede ni debe más sino decir la verdad"50 pudo haber sido firmada por todos nuestros autores.

Además de imparcial, el historiador debía ser de buena fe y estar dispuesto a despojarse de sus propias opiniones

\footnotetext{
49 Castillo Negrete, México, 1875-1892, vol. 1, p. 4 .

${ }^{50}$ Riva Palacio, "El virreinato", en Riva Palacio et al., México, 1980, vol. 3, p. XII.
} 
y afectos. Para algunos de nuestros personajes, como Juan de Dios Arias, era éste "un mandato que siempre ha sido de dificil cumplimiento". Sin embargo pensaba que "estos escollos" se podían salvar "a fuerza de prudencia, de imparcial examen, de investigación minuciosa y sobre todo de la elección de buenas tradiciones y del acopio de documentos de intachable autenticidad".$^{51}$ Es evidente que esta tarea requería de mucho tiempo y de gran dedicación, por lo que no es de extrañar que Manuel Rivera Cambas dejara asentado que "los trabajos históricos jamás presentan la lucidez que corresponde al tiempo y a las fuerzas consumidas ni dan idea de todo lo que cuesta desenterrar noticias de entre el pesado polvo de los siglos". 52

La misión última de la historia era funcionar como un tribunal, por lo que el historiador debía rendir culto a la justicia. Al decir del propio don Manuel, éste no podía "excusarse de darla a todos aquellos que a su juicio la mereciesen". 53 Así, Riva Palacio afirmaría a su vez que "la severa imparcialidad de la historia" debía juzgar a los hombres y a los acontecimientos sin preocuparse del efecto que su fallo produciría en las presentes o venideras generaciones. 54

Por lo general, y parafraseando las palabras de Zárate, nuestros hombres de letras consideraron a la historiop. vili.

S1 Juan de Dios Arias, "México", 1980, vol. 7,

${ }_{52}$ Rivera Cambas, Gobernantes, 1872, vol. 1 , p. XII.

53 Ibid., vol. 1, p. viI.

${ }^{54}$ Riva Palacio, "El Virreinato", en Riva Palacio et al., México, 1980, vol. 3, p. XII. grafia como una narración que recoge y conserva la tradición y la memoria, a despecho del tiempo y del pasado. ${ }^{55}$ Como tal, sus lecciones ayudaban a la comprensión del pasado pero, sobre todo, al decir de Castillo Negrete, "servían de guía, de luz" y permitían "marchar con paso seguro, pero sin desviar nuestra vista de ella, a semejanza del marino que fija su mirada para llegar al puerto, en la estrella polar". ${ }^{56}$ Es evidente que esta concepción utilitarista de la historia, muy cercana a la visión clásica de Cicerón en cuanto a que era maestra de la vida, permitió que el quehacer de Clío se convirtiese en una materia esencialmente política, de la que se serviría el Estado para construir una conciencia histórica que integrase a la nación.

\section{A MANERA DE CONCLUSIÓN}

Varias son las autoridades que han sostenido que el siglo XIX fue el siglo de la historia y de los grandes historiadores. Cabía esperar que una centuria predominantemente romántica y nacionalista se consagrase a recuperar el pasado para dar sentido a su presente. Nuestro país no podía quedar excluido de dicha corriente universal. Su propia circunstancia de inestabilidad política continua, que culminó en una guerra civil y en una segunda intervención extranjera, hizo que la victoria definitiva del partido liberal sobre el conservador se tornara en un acicate para buscar la unión de todos los mexi-

55 Zárate, op. cit., vol. 6, p. 363.

56 Castillo Negrete, México, 1875-1892, vol. 1, pp. 4 y 10. 
canos en torno a un pasado común y a un régimen político triunfante. El partido vencedor, que necesitaba consolidar su dominio tanto político como ideológico, inició el proceso de construcción de su legitimidad a través de la historiografia. Por ello, así como Charles Hale sostiene que a partir de 1867 el liberalismo dejó de ser una ideología combativa para convertirse en un mito unificador, nosotros añadiríamos que este mito se fue labrando a través del quehacer historiográfico emprendido básicamente por los hombres de letras de la generación tuxtepecana.

\section{BIBLIOGRAFIA}

-Altamirano, Ignacio M. et al., Hombres ilustres mexicanos. Biografias de los personajes notables desde antes de la conquista hasta nuestros días, $2 \mathrm{a}$. edición, Editorial Nacional, México, 1958, 4 vols.

-Álvarez, Ignacio, Estudios sobre la historia general de México, Imprenta Económica de Mariano Ruiz de Esparza, Zacatecas, 1875-1877, 6 vols.

-Barreda, Gabino, Estudios, prólogo de José Fuentes Mares, UNAM, México, 1941 (Biblioteca del Estudiante Universitario).

-Camelo, Rosa (coord.), Historiografía mexicana (en prensa), vol. IV.

-Castillo Negrete, Emilio del, México en el siglo XIX, Imprenta en Escalerilla 3, México, 1875-1892, 29 vols.

Galería de oradores de México en el siglo XIX, Tipografía de S. Sierra, México, 1877-1880, 2 vols.

-Dublán, Manuel y José María Lozano, Legislación mexicanao colección completa de las disposiciones legislativas desde la independencia de la República, Imprenta del Comercio, México, 1876-1904.
-García Cubas, Antonio, Compendio de la historia de México y de su civilización, 2a. edición, Antigua Imprenta de Murguía, México, 1893.

-Garritz, Amaya (coord.), Un hombre entre Europa y América. Homenaje a Juan Antonio Ortegay Medina, IIH-UNAM, México, 1993.

-González y González, Luis, La ronda de las generaciones, SEP-Cultura, México, 1984.

-Guizot, François, Histoire de la République d'Angleterre et de Cromwell, Florkin et Ken, Bruselas, 1854.

-Hale, Charles, La transformactón del liberalismo en México a fines del siglo XIX, Vuelta, México, 1991.

-Martínez, José Luis (comp.), La literatura nacional, Porrúa, México, 1949.

-Ortega y Medina, Juan A., Polémicas y ensayos en torno a la historia, IHH-UNAM, México, 1970.

-Payno, Manuel, Carta que sobre los asuntos de México dirige al Sr. General Forey, Comandante en jefe de las tropas francesas..., García Torres, México, 1862.

-Paz, Ireneo, Algunas Campañas, 2 a. edición, Imprenta y Litografia La Patria, 1884.

Los hombres prominentes de México, Imprenta y Litografia La Patria, México, 1888.

Maximiliano, Imprenta y $\mathrm{Lj}$ tografía La Patria, 2a. edición, 1899.

-Perales, Alicia, Asociaciones literarias mexicanas, siglo $X I X$, Imprenta Universitaria, México, 1957.

-Prieto, Guillermo, Lecciones de Historia Patria, Introducción de Carlos Monsiváis, INBA/SRP/INEHRM, 1986.

-Riva Palacio Vicente, Los cuentos del general y Los Ceros, Galería de contemporáneos, pról. de José Ortiz Monasterio, Promexa Editores, México, 1979. , et al., El libro rojo de México, pról. de Carlos Monsiváis, Litografia Maico, México, 1988, 3 vols. 
México a través de los siglos, Editorial Cumbre, México, 1980, 10 vols.

- Rivera Cambas, Manuel, Los gobernantes de México. Galería de biografíasy retratos de virreyes, emperadores, presidentes y otros gobernantes que ha tenido México desde Don Hernando Cortés has. ta el C. Benito Juárez, Imprenta de Aguilar Ortiz, México, 1872:1873, 2 vols.

México pintoresco, artístico

y monumental, Imprenta Reforma, México, 1880-1883, 3 vols.

, Historia de la intervención europea y norteamericana en México y del imperio de Maximiliano de Habsburgo, INEHRM, México, 1987, 3 vols.
-Roldán Vera, Eugenia, "Conciencia histórica y enseñanza; un análisis de los primeros libros de texto de historia nacional. 1852-1894", tesis de licenciatura, Facultad de Filosofia y Letras-unAM, México, 1995.

-Vázquez Bravo, Luz Helena, "Un alzado porfirista se pronuncia: 'una historia para el pueblo' ", tesis de licenciatura, ENEP/ Acatlán-UNAM, México, 1992.

\section{HEMEROGRAFÍA}

-El Renacimiento

-El Siglo Diez y nueve 